2020-03

Preparation and support for students in community placements: A mixed methods study

Williamson, Graham

http://hdl.handle.net/10026.1/15465

10.1016/j.nepr.2020.102747

Nurse Education in Practice

Elsevier BV

All content in PEARL is protected by copyright law. Author manuscripts are made available in accordance with publisher policies. Please cite only the published version using the details provided on the item record or document. In the absence of an open licence (e.g. Creative Commons), permissions for further reuse of content should be sought from the publisher or author. 


\section{PREPARATION AND SUPPORT FOR STUDENTS IN COMMUNITY PLACEMENTS: A MIXED METHODS STUDY}

\section{Abstract}

Community nursing needs to expand its workforce in the United Kingdom in the immediate future, to accommodate the requirements of an ageing population and the rationalisation of care delivery to community settings resulting from Sustainability and Transformation Plans. It has been reported internationally that student nurses do not always value or learn from their community placements and that this may contribute to an apprehension regarding working in the sector after graduation. This mixed methods study, using a survey and a focus group, investigated students' views of their community placement experiences in relation to the learning environment, their clinical facilitator and the use of a structured learning package to prepare and guide development of skills and knowledge. The triangulated data indicate that students enjoyed their community placements as learning environments, had excellent relationships with their clinical facilitators, and would welcome a more structured information package as an approach to preparation and placement learning.

\section{Highlights}

- Some student nurses do not enjoy or appreciate their community placements.

- This reluctance means they may not view community nursing as a postgraduate destination.

- Our study contradicts this view point.

- Our students enjoyed their community placements.

- Our students favoured a structured information package for placement learning. 


\section{Keywords}

Student nurses; community nursing; placement learning; mixed methods research; survey; focus group.

\section{Acknowledgements}

Thanks are due to the following people, who were involved in this study but do not meet the criteria for authorship:

Beth Hawkes ${ }^{a}$ and Fiona Cook ${ }^{a}$ lecturers in community nursing, who contributed to the information packages.

Kara Mundy ${ }^{\mathrm{c}}$ recent University of Plymouth BSc Adult Nursing graduate and Community Nurse, whose undergraduate academic work provided some of the literature for this paper.

'Royal Devon and Exeter NHS Foundation Trust, Rolle Medical Partnership, Claremont Grove, Exmouth, Devon. EX8 2JF. UK

\section{Introduction}

Primary care has been defined as healthcare professionals delivering services in the local community; this includes community nurses providing care to patients within their own homes (Department of Health and Social Care, 2013) and in general practice settings. National and international demographics indicate that community nursing is an ageing workforce (QNI, 2014, Ryan et al., 2018), so there is a pressing need to attract graduate nurses to community nursing careers, ensure quality student placements with effective support to maximise learning opportunities (Edgecombe et al., 2012). Evidence suggests there has been an unbalanced focus on acute care (Queen's Nursing Institute, QNI, 2014). In the future, patients receiving care at home will become the largest patient group, leading to an increased need for community nurses (World Health Organisation, 2011). The current shortage of community nurses in the UK is problematic: community nurse teams' numbers and skill mix are not reflective of the shift in nursing care away from the acute sector, arguably leaving them currently insufficiently equipped to deliver effective 
healthcare to the population (The King's Fund, 2016). The requirement for an appropriately skilled community workforce has been made more pressing since the introduction to the United Kingdom National Health Service (UK NHS) of Sustainability and Transformation Plans (STPs, The Kings Fund, 2017), which have a specific focus on community care, service redesign to locate care in the community instead of the acute sector, preventative health, integrated care and developing the workforce to enable those objective to be met (Alderwick and Ham, 2017). The NHS (2014) Five-Year Forward View aimed for out-of-hospital care to evolve as more care than ever is being delivered in the community setting. The Nursing and Midwifery Council (NMC, 2018) have considered this issue in the updated pre-registration nurse education standards, incorporating elements of primary care into the curriculum, and this has long been recommended by the Royal College of Nursing (RCN, 2007). Whilst many Higher Education Institutions (HEIs) have incorporated a requirement for community placements within their programmes, securing placements especially within GP practices has been notoriously difficult (Marsland and Hickey 2003). However, it is evident that the majority of nursing students upon registration choose to work within acute settings with only limited numbers choosing to work within the community (McCann, et al., 2010). Limited opportunities for placement experience and negative perceptions and attitudes towards working in the community can mean that the roles are often undervalued (QNI, 2014; Abrams, 2016).

The extent to which community placements meet students' learning needs is problematic and the international literature is divided on this. In Sweden, Sundler et al. (2014) describe how student nurses enjoyed their community placements. A number of factors can be attributed to this such as, closer working with mentors (Murphy et al., 2012), the ability to build therapeutic relationships with patients and carers, the continuity to take a whole person approach and the development of autonomous practice. In their Welsh study about students' perceptions, Murphy et al. (2012) found no differences between students' views of nursing in hospital and in the community; and unlike other studies, students expressed a preference for district nursing (Murphy, et al., 2012). The quality of clinical placements is one of the greatest impacts upon a student's journey to become a nurse, but not all clinical 
placements are beneficial to learning (Shivers et al., 2017), and it is clear from a systematic review that placement-related student nurse attrition is complex, multifaceted, but is associated with being exposed to unpleasant placement experiences, attitudes of placement staff, and lack of support (Eick et al., 2011). In their Canadian work, Babenko-Mould et al. (2016) argue that students can be apprehensive about working in the community, in part because of the perception of being outside of the structured hospital environment. In United States, Maneval and Kurz (2016) agree that students can be worried about working in the community, particularly about their personal safety.

Albutt et al.'s (2013) UK study found that, at that time, nurse education programmes did not adequately prepare student nurses to practice in primary care, and that curricula were still heavily focused on acute sector nursing care, a finding also recognised in New Zealand by Betony and Yarwood (2013). This might bias students' preferences away from the community as a postgraduate destination, and was identified in Australia as contributing to a shortage of newly qualified community nurses (McCann, et al., 2010). In the Netherlands, community nursing was seen as a lower status occupation than acute sector nursing, and many students were not keen on community placements or working there as a career on graduation (lersel, et al., 2018). Interestingly, Schneider et al. (2018) facilitated student health professionals to take part in a social learning program. The program was based in Colombia where Schneider et al. (2018) describes factors such as displacement of families due to political issues has led to areas of deprivation in need of community based care. The study found that the students involved in the project enjoyed working autonomously and creatively and that by working in areas of deprivation they felt that has become more compassionate (Schneider et al., 2018). The benefits of student nurses having exposure to community nursing is also advocated by other international authors such as Kent-Wilkinson et al. (2010), who describe student nurses having to personalise and adapt their practice when caring for Australian Aboriginal children in community setting in order to recognise cultural needs. 


\section{Methods}

Aim

The aim of the study was to investigate student nurses' experiences of their preparation and learning whilst undertaking community placements in the South West peninsula of England. The objective was to inform the development of a structured information package for students regarding nursing in community placements.

\section{Design}

This was a mixed methods study, including a survey to all adult field student nurses as well as a focus group to investigate issues in more detail. The survey element involved administration of the abbreviated Clinical Learning Environment Inventory (CLEI-19, Salamonson et al., 2011). The long form CLEI (Chan, 2002) contains 42 items, and although this has high face validity, it is unwieldy to complete and some items show low Cronbach's alpha values for reliability (Perli and Brugnolli, 2009). In response to this, Salamonson et al. (2011) developed and tested an abbreviated version, with 19 items from the original CLEI common in all learning environments; these generic domains being the clinical facilitator and students' satisfaction with the clinical setting. Cronbach's alpha coefficient was 0.93 for the total CLEI-19, with subscales ranging from 0.92 to 0.94 . Thus Salamonson et al. (2011) conclude that the CLEI-19 is a valid, reliable and useful measure to explore nursing students' satisfaction with clinical facilitator support and the clinical learning environment, which is significantly shorter and less unwieldy to administer that the long form. We used the CLEl-19 with kind permission from Salmonson. We added a $20^{\text {th }}$ question about the type of placement that students had undertaken last, either community/district nursing or General Practice (GP) nursing and made it clear that we were asking students to evaluate their last placement when considering the CLEI19 items.

The focus group (FG) was planned in order to gain a more depth insight into students' perceptions of their community placements. A semi-structured schedule of questioning was developed in advance of the FG by the research team (see table 1). 
1) What sort of community nursing placement have you had?

2) Did you/do you feel prepared to go into community nursing practice placements?

a) What kind of preparation did you receive and undertake yourself for your community placement?

3) How might a more structured approach have helped with this?

a) Would these have been useful to you before you went to a community placement?

b) Do you like the information, detailed structure, presentation and so on of the drafts you have seen?

4) How might this structure be made effective?

a) Which is more useful, an on-line version or a paper version?

b) How might we pilot these? Would practitioners use them? How could we make sure they were used effectively?

Table 1: Semi-structured questions for the focus group.

Focus groups reflect the interactions between participants to allow exploration and elaboration of ideas that may not have occurred otherwise, and generate data that is influenced by the synergies between group members (Cleary et al., 2014). Although there is no consensus on the optimum size for FGs; Cleary et al. (2014) indicate that 2-4 participants would be too few, but even so, careful moderation is required to make sure participants get approximately equal opportunities to be heard and that one or two members do not dominate proceedings (McLafferty, 2004).

\section{Ethics}

Ethical approval to conduct the study was gained from the Faculty Research Ethics committee. Students were guaranteed the usual rights to confidentiality and anonymity, and that non-participation would not interfere with their relationship with staff or the university. The CLEI-19 survey was administered using SurveyMonkey, which has a setting that means no identifying data whatsoever is collected, not even the IP address. As the data collected were completely anonymous at source, it could not subsequently be withdrawn. This was explained in the participant information sheet (PIS), where it was also noted that completion and submission of the survey would be taken to indicate consent to use the data. In the FG, the right to withdraw data at a later date was possible (although no students did so) and written informed consent was gained from all participants in conjunction with the PIS. 


\section{Recruitment and data collection}

Data collection was undertaken in March-May 2018, in one University School of Nursing and Midwifery in the South West of England. All second and third year adult field students were invited using their university cohort email addresses to complete the CLEI-19. The survey closed in early May 2018. We did not invite first year students as we could not be sure that they had all undertaken community placements at that point in their programmes. An invitation to participate was emailed, including the PIS, with a link to click through to SurveyMonkey to complete the survey. These emails contained an invitation to volunteer for the FG, which lasted approximately half an hour, was held on the main university campus and conducted by a member of the research team. Two reminders were sent. The FG took place in April 2018. We received 9 volunteers. Ahead of the FG, those volunteers were provided with structured learning packages about community and GP nursing, designed to improve preparation and placement learning, which were developed by members of the research team.

\section{Data analysis}

The CLEl-19 was analysed using simple descriptive statistics not inferential statistics because we believed that inferential statistics are inappropriate where non-random sampling methods have been used (Williamson, 2003). We also calculated a mean weighted average for all 19 items. Our $20^{\text {th }}$ question about the type of community placement students had last undertaken was also analysed descriptively.

The focus groups was digitally recorded and thematically analysed using the recognised qualitative approach from the 'Framework' Method (Ritchie et al., 2014). This is popular and influential for healthcare researchers as it offers a systematic approach to qualitative data analysis (Gale et al., 2013). It involves six sequential stages, moving from familiarisation with the interview, coding of data, developing and applying an analytical framework, charting the framework and interpreting the data. These processes were undertaken independently by the four-member research team, and final interpretations discussed and agreed between us. 


\section{Rigour and triangulation}

As Morse et al. (2002) argue, criteria for establishing the rigour research need to be built into the design and conduct of the research study, not applied post-hoc. In this study the principles of credibility and dependability were applied to enhance transferability and trustworthiness (Graneheim and Lundman, 2004) by the following means: credibility and dependability were assured by purposively sampling students whom we believed would have had experience of community placements, which was second and third year cohorts but not first years. We also sought accurately to represent the views of students in the FG by careful attention and reporting of themes with illustrative quotes, which we have done below, and independently analysing and agreeing the final analysis between three members of the research team. The FG was undertaken by a qualitative researcher and lecturer in community nursing, who was careful to allow the voices of participants to be heard and did not impose her opinions on the FG. She repeatedly sought to gain perspectives from different members of the group. Transferability is demonstrated by description of the context and selection processes of participants (as far as duty of confidentiality and anonymity allow) as well as transparency regarding data collection and analytic procedures. This we believe that trustworthiness is high.

As a further step in rigour, we undertook methods triangulation, which involved combining and interpreting data from the qualitative FG data and CLEI-19 survey, to allow the limitations of each method to be transcended and allow a perspective to emerge that takes into account differences in those methods. In this study data was considered together in order to add depth and richness to our understanding (Heale and Forbes, 2013) and this required discussion and judgement concerning the extent to which findings from both sources complemented or contradicted each other (Williamson, 2005).

\section{Findings}

\section{Clinical Learning Environment Inventory data}

The CLEI-19 was emailed to 850 adult field students. The response rate was $23.5 \%$ $(n=200)$. The mean weighted score for all 19 items was 4.05 (on a scale of 1-5), indicating that students' experience of community placements (including 
community, district and GP practice nursing) was overwhelmingly positive. For our additional question, Question 20,87\% ( $n=171)$ had undertaken community/district nursing and $13 \%(n=25)$ GP nursing as their last community placement, so the weighted mean score is further skewed to reflect students' community/district nursing experiences. We were not able to analyse the data to compare and contrast responses between placement types as we were not able to identify individual answers in the dataset because of the anonymity imposed in SurveyMonkey. We did not collect data on the gender of the respondent as we did not see its direct relevance to the study and did not plan to investigate gender as a variable, but as our adult field cohorts are $95 \%$ female the results will reflect this. The full data set is available in Appendix A. We do not report in detail the results for every item here, however, the following are particularly noteworthy: that $89 \%$ of students disagreed or strongly disagreed with Question 13 'The placement was boring', and 88\% agreed or strongly agreed with Question 19 that the placement was interesting. Eighty percent disagreed or strongly disagreed with the statement that they were dissatisfied with the placement (Question 5), and 84\% agreed or strongly agreed that they experienced a sense of satisfaction after the shift (Question 7). A slightly less positive connotation in the results was regarding Question 9, 'The clinical facilitator thought up innovative activities for students', where $40 \%$ of respondents disagreed or strongly disagreed with this proposition. However, $61.5 \%$ of respondents agreed or strongly agreed with Question 16 that 'The clinical facilitator often thought up interesting activities'. None of the other items about the relationship with the clinical facilitator demonstrated negative connotations.

\section{Focus group data}

Three themes from the FG emerged, broadly reflecting the schedule of questioning, these being: Preparation, Structure and Piloting.

\section{Preparation}

There was some disagreement amongst participants as some felt prepared to go into their community placements, some did not. Those who felt unprepared believed more could be done regarding preparation from a university perspective: 
I was a direct entry student [a trust sponsored student with a foundation degree who begins the BSc in year two] and we had a lot of trouble with our placements...so I was not prepared at all and felt a bit "thrown in at the deep end" and it was my first placement...ever! (Participant 2).

Those students that believed themselves to be adequately prepared listed induction materials from the placement as helpful; one student had attended a specific induction day in placement which included activities, which another student would also have favoured; a third student was reassured about their community placement after meeting placement staff. Several students mentioned useful links, particularly to RCN materials:

I read around the subject area myself and I did go to an induction day [in placement], which was mandatory...they taught me, "learning by doing", a little activity, so that was quite good (Participant 1).

I read up on the RCN website, where you can do little quizzes about wounds, and things that I would be doing. The when I got to placement they gave me a big induction pack, which was really useful. (Participant 4).

It was better once I'd been to the placement and I felt better prepared once I'd chatted to them [placement staff] in person. (Participant 3).

\section{Structure}

A structured approach to community placement preparation and learning was welcomed by most of the students in the FG, and this was particularly the case when materials and ideas it might include could contribute to their placement learning assessment outcomes (called the Ongoing Achievement record, or OAR). Students seemed to want a structured approach, with specific direction about useful clinical learning activities and reading:

A more structured approach would have helped with my learning outcomes, helped me to feel more prepared... I always ask before my placements "What should I read 
up on" and they say "Oh just read about leg ulcers" [general laughter] and you think "Oh there must be more" or ...it's really nice to have that direction about what specifically to look at. You know what you're going into a bit more. (Participant 1).

Yeah it would have been useful [structure relating to] the learning outcomes in the OAR. (Participant 2).

When presented with detailed ideas about how such structured preparation and learning might look, they did not favour an excess of written materials, finding some elements 'daunting' and unhelpful where overly long:

I think it would be good to have more structure and things you'll see in the community [but not too much] (Participant 4).

Not so much that it's overwhelming (Participant 3).

This was particularly the case when the materials appeared only peripherally relevant to placement learning as the students perceived it:

The thing about having too much information, how does that relate to [interviewer: the education theory?]...yeah, although it's interesting...for placement, "What do I need to know, what's the essential things, what are they going to ask me" and it's quite unlikely that a community nurse is going to ask me about how I'm learning rather than what I'm learning. (Participant 5).

Keep it simple, if there's too much information I'm more likely to put it to one side and do my own thing, like [use] Google. (Participant 6).

Links to websites or dedicated apps (smart phone applications) might fulfil a need for highly focused placement related information, in the same way that the British National Formulary (BNF, a joint development of the British Medical Association and the Royal Pharmaceutical Society; see https://www.bnf.org/products/bnfbnfcapp/ ) app for medications management is portable on a smartphone. 
Students believed that study materials would be useful in quiet times such as when mentors were busy with paperwork and other activities that the students could not help with. Thus students could productively fill the time by utilising some relevant, guided study whilst in a 'natural pause' in placement, on a daily basis, to keep busy rather than be idle:

My mentor told me about the Devon formulary [South \& West Devon Formulary and Referral. A website from an initiative for safe and effective care and prescribing in Devon by the Clinical Commissioning Groups; see

https://southwest.devonformularyguidance.nhs.uk/ ] and you can have that as an app, and I found that really useful...So it shows you algorithms, so if you are unsure of the process for [clinical treatments] it gives you what to do. (Participant 3).

It was an RCN link...you went through things, and I went through it and printed off the certificates as evidence for my OAR and I learned a lot. And that's really good to do when the community nurses are doing their office work. [General agreement]...useful to have something to do so I could sit there and learn and be busy rather than just sit there and feeling useless. (Participant 5).

It was noted that internet access was sometimes problematic and there was therefore a place for printed materials.

\section{Pilot}

Students believed that a more structured approach to preparation and learning would be valuable in their community nursing, and that this needed to be shared with all their mentors:

The mentors would need to know, obviously. There's nothing worse than going in and going to your mentor "I've got to do this" and the mentors don't know... anything about it. (Participant 1).

Communication (Participant 2).

It would be important that the mentors knew how it worked, so then you could work as a team with them. (Participant 9). 
Some students indicated that it could usefully be added to their practice assessment documentation:

It could become part of your OAR document in that, when you go in, you set your learning outcomes, you take [any new materials] with you, and you use it to that supplement...it gives substance to what your learning outcomes are (Participant 8).

Other students indicated that there would be an obvious need for a planned pilot and implementation strategy, with training for all stakeholders, feedback and involvement of PALS (Peer Assisted Learning Scheme, in which senior students help junior ones with aspects of their programmes of study, including in clinical practice) in development, implementation and evaluation:

See how that works with the PALS leaders, see how they pass that information on, and then try it again with a smaller groups, and see if it works, rather than release it all at once. (Participant 4).

Yeah definitely with smaller groups. (Participant 3).

Nice to see an example of how it works. (Participant 8).

\section{Discussion}

The triangulated data indicated that here was not substantial disagreement between the qualitative and quantitative data sources. In our triangulation of the data, we were able to conclude that students in this study enjoyed their community placements as learning environments, had excellent relationships with their clinical facilitators, and would welcome a more structured information package as an approach to preparation and placement learning. It would appear that access to clinical information and relevant specialist apps could be important in this, particularly where this linked to placement assessment. As we had solid positive evidence from the CLEl findings, linking this with the FG data means we are 
confident that our community placements were valuable and that there was no overwhelming need to add structure to improve matters, but that this might add an additional element of direction that would be beneficial to students' learning As placement dissatisfaction, relationship with mentors and unpleasant experiences in practice are major contributing factors to student attrition from programmes (Eick et al., 2013); it is heartening that our students found the learning environment and the relationship with clinical facilitators overwhelmingly positive in our region.

International literature indicates a mixed picture concerning the extent to which students enjoy their community placements internationally (Babenko-Mould et al., 2016, Cooper et al., 2014, Schneider et al., 2018, Kent-Wilkinson et al., 2010, Betony and Yarwood 2013) which may contribute to reluctance to work in the community post-graduation (Albutt et al., 2013), and Pijl-Zieber et al. (2015) go further, saying there is frequently a disconnect between students and their community placement preparation and learning that amounts to a substantial theory-practice gap related to the lack of a strong community-focused pedagogy. This appears not to be the case in our study as students overwhelmingly reported satisfaction with their clinical facilitation and learning environment in the CLEI-19 data. Students in the FG were largely supportive of the concept of a more structured approach to their perpetration and learning, provided that this was clinically focussed, indicating that they welcomed a clearer pedagogy so long as this was not based only in educational theory. This is instructive and provides a means to ensure that students receive targeted learning before and during their community placements, which would help them value the experience more fully, and might address some of the negative pedagogical influences reported internationally (Pijl-Zieber et al., 2015).

The CLEI-19 data indicated that there was a potential issue with a lack of innovative thinking amongst some clinical facilitators, and this was supported in part in the FG where students reported sitting around with little to do when their mentors were busy doing paperwork on computers. Perceived failings around innovation are reported elsewhere in community placement learning for students (Harwood et al., 2009), but our students were clear that periods where patient visits were not taking place could be filled with effective placement learning using a structured approach, 
with one student highlighting clinical app usage such as The Devon Formulary, which appears innovative and is consistent with the expectation of technology enhanced learning common amongst Millennials (Blue and Henson, 2015).

\section{Limitations}

The research took place in one University School of Nursing, and therefore our findings are context and location specific. However, we believe that they have some transferability to other similar settings as we have followed rigorous processes in the design and conduct of the research.

It is widely reported that response rates from internet surveys are much poorer that other means of recruitment (McPeake et al., 2014), and indeed one comparative study could only generate a $2.9 \%$ response rate for internet methods, even when the survey was personalised (Sinclair et al., 2012). Therefore we argue that a response rate of $23.5 \%$ for our survey was in fact satisfactory. We accept that there is some nonresponse bias in the results because we did not get responses from our whole population, the implication being that the survey results do not accurately reflect the true opinions of all our students (Halbesleben and Whitman, 2012); however, as the survey was completely anonymous and completed in private, we believe that social desirability bias is negligible in our results (Gittleman et al., 2015).

\section{Conclusion}

The UK is currently experiencing a shortage of community nurses, predicted to worsen due to the country's aging population and the shift in healthcare from secondary to primary care, and this shortage appears to be a global phenomenon (The King's Fund, 2016; World Health Organisation, 2011). In the UK, new NMC (2018) standards for nurse education emphasise the need for effective community placement learning, and this may link to improvement recruitment in the sector in the future. This study indicates that, in contrast to some international studies (Babenko-Mould et al.; 2016) our respondents enjoyed their community placements. They also welcomed some structured learning resources that were clinically focused, as an adjunct to their learning. We recommend that further work needs to take place on the format and content of any such resources, although it appears useful to 
consider electronic delivery modes, in keeping with Millennials' learning needs (Blue and Henson, 2015). These should be developed and evaluated in collaboration with practitioners, with rigorous processes of piloting and implementation. Whilst local needs would dictate specific details in any resources, we recommend that further developments might usefully be conducted at national level and further research would be required to evaluate this activity.

\section{Appendix A. Supplementary data}

Supplementary data to this article can be found online at https://pearl.plymouth.ac.uk/handle/10026.1/12458 


\section{References}

Abrams, V (2016) I feel a bit naughty for saying that I wish to work in a different setting than a hospital. Retrieved from https://www.nursingtimes.net/students/idont-want-to-work-in-a-hospital-there-ive-said-it/7002188.article

Albutt, G., Ali, P., and Watson, R., 2013. Preparing nurses to work in primary care: educators' perspectives. Nursing Standard, 27(36), 41-46.

Alderwick, H., and Ham, C., 2017. Sustainability and transformation plans for the NHS in England: what do they say and what happens next? BMJ; 356 :j1541

Babenko-Mould, Y., Karen, F., Stephanie, A., 2016. Neighbourhood as community: A qualitative descriptive study of nursing students' experiences of community health nursing. Nurse Education in Practice 17, 223-228.

Betony, K., Yarwood, J., 2013. What exposure do student nurses have to primary health care and community nursing during the New Zealand undergraduate Bachelor of Nursing programme? Nurse Education Today 33, 1136-1142.

Blue, C., and Henson, H., 2015. 'Millennials and Dental Education: Utilizing Educational Technology for Effective Teaching', Journal of Dental Hygiene, 89, 46-47. Chan, D., 2002. Development of the clinical learning environment inventory: using the theoretical framework of learning environment studies to assess nursing students' perceptions of the hospital as a learning environment. J. Nurs. Educ. 41(2), 69.

Cleary, M., Horsfall, J., Hayter, M., 2014. Data collection and sampling in qualitative research: Does size matter? Journal of Advanced Nursing. 70, 473-475.

doi:10.1111/jan.12163

Department of Health and Social Care, 2013. The health and care system explained. London: Department of Health and Social Care.

Edgecombe, K., Jennings, M., and Bowden, M., 2012. International nursing students and what impacts their clinical learning: Literature review. Nurse Education Today, 33(2), 138-142. 
Eick, S.A., Williamson, G. R., and Heath, V., 2012. A systematic review of placementrelated attrition in nurse education. International Journal of Nursing Studies 49(10),1299-309. https://doi.org/10.1016/j.ijnurstu.2011.12.004

Gale, N.K., Heath, G., Cameron, E., Rashid, S., Redwood, S., 2013. Using the framework method for the analysis of qualitative data in multi-disciplinary health research. BMC medical research methodology 13, 117-117.

Gittelman S., Lange V., Cook W. A., 2015. Accounting for Social-Desirability Bias in Survey Sampling. Journal of Advertising Research. 55(3), 242-254. doi:10.2501/JAR2015-006.

Graneheim, U. H., and Lundman, B., 2004. Qualitative content analysis in nursing research: concepts, procedures and measures to achieve trustworthiness. Nurse Education Today, 24(2), 105-112.

Halbesleben, J. R. B., and Whitman, M. V. 2013. Evaluating Survey Quality in Health Services Research: A Decision Framework for Assessing Nonresponse Bias. Health Serv Res. 2013 48(3), 913-30. doi: 10.1111/1475-6773.12002.

Heale R., and Forbes D., 2013. Understanding triangulation in research. Evid Based Nurs. 16(4), 98. doi: 10.1136/eb-2013-101494.

Harwood, H. C., Reimer-Kirkham, S., Sawatzky, R., Terblanche, L., Van Hofwegen, L., 2009. Innovation in community clinical placements: a Canadian survey. Int. J. Nurs. Educ. Scholarsh. 6 (1), 28. http://dx.doi.org/10.2202/1548-923X.1860.

lersel, M., Latour, C., Vos, R., and Kirschner. 2018. Perceptions of community care and placement preferences in first-year nursing students: A multicentre, crosssectional study. Nurse Education Today, 60, 92-97.

Kent-Wilkinson, A., Starr, L., Dumanski, S., Fleck, J., LeFebvre, A., Child, A., 2010. International Nursing Student Exchange: Rural and Remote Clinical Experiences in Australia. Journal of Agromedicine 15, 58-65.

The King's Fund, 2016. Understanding quality in district nursing services: Learning from patients, carers and staff, London: The King's Fund. 
The King's Fund, 2017. Sustainability and Transformation Plans explained. Retrieved from https://www.kingsfund.org.uk/topics/integrated-care/sustainabilitytransformation-plans-explained.

Maneval, R.E., Kurz, J., 2016. "Nursing Students Assaulted": Considering Student Safety in Community-Focused Experiences. Journal of Professional Nursing 32, 246 251.

Marsland L, Hickey G. 2003. Planning a pathway in nursing: do course experiences influence job plans? Nurse Education Today. 23(3):226-35.

McCann, T., Clark, E. \& Lu, S., 2010. Bachelor of nursing students' career choices: A three year longitudinal study. Nurse Education Today, 30(1), 31-36.

McLafferty, I., 2004. Focus group interviews as a data collecting strategy. J Adv Nurs, 48, 187-194.

McPeake, J., Bateson., M, O’Neill A., 2014. Electronic surveys: how to maximise success. Nurse Researcher. 21(3), 24-26.

Morse, J,M., Barrett, M., Mayan, M., Olson, K., and Spiers, J., 2002. Verification Strategies for Establishing Reliability and Validity in Qualitative Research. International Journal of Qualitative Methods, 1(2), 13-22. https://doi.org/10.1177/160940690200100202 Murphy, F., Rosser, M., Bevan, R., Warner, G., Jordan S., 2012. Nursing students' experiences and preferences regarding hospital and community placements. Nurse Education in Practice, 12, 170-175.

National Health Service, 2014. The Five-year forward view. Retrieved from https://www.england.nhs.uk/publication/nhs-five-year-forward-view/ National Health Service, (2017) Next Step on The Five-year forward view. Retrieved from https://www.england.nhs.uk/wp-content/uploads/2017/03/NEXT-STEPS-ON$\underline{\text { THE-NHS-FIVE-YEAR-FORWARD-VIEW.pdf }}$ 
Nursing and Midwifery Council (2018) Realising professionalism: Standards for education and training. Retrieved from https://www.nmc.org.uk/standards-for-education-andtraining

Perli, S., and Brugnolli, A., 2009. Italian nursing students' perception of their clinical learning environment as measured with the CLEI tool. Nurse Education Today 29(8), 886-890.

Royal College of Nursing, 2017. Helping students get the best from their practice placements A Royal College of Nursing toolkit. Retrieved from https://www.rcn.org.uk/professional-development/publications/pub-006035

Ryan, C., Bergin, M., White, M., Wells, J.S.G., 2018. Ageing in the nursing workforce a global challenge in an Irish context. International Nursing Review.

https://doi.org/10.1111/inr.12482

Salamonson, Y., Bourgeois, S., Everett B., Weaver, R., Peters, K. and Jackson, D., 2011. Psychometric testing of the abbreviated Clinical Learning Environment Inventory (CLEI-19). Journal of Advanced Nursing, 67(12), 2668-2676.

Sinclair, M., O'Toole, J., Malawaraarachchi, M., and Leder, K., 2012. Comparison of response rates and cost-effectiveness for a community-based survey: postal, internet and telephone modes with generic or personalised recruitment approaches. BMC Med Res Methodol., 12: 132. doi: 10.1186/1471-2288-12-132

Pijl-Zieber, E. M,. Barton, S., Awosoga, O., and Konkin, J., 2015. Disconnects in pedagogy and practice in community health nursing clinical experiences: Qualitative findings of a mixed method study. Nurse Education Today 35, e43-e48.

Queens' Nursing Institute. 2014. Developing a national District Nursing workforce planning framework. QNI/NHS England. PUBLICATIONS GATEWAY REFERENCE 01518. Retrieved from https://www.qni.org.uk/wpcontent/uploads/2016/09/district nursing workforce planning report.pdf 
Ritchie, J., Lewis, J., Nicholls, C., M., Ormston, R., 2014. Qualitative Research Practice: A Guide for Social Science Students and Researchers. Second Edition. London, SAGE.

Shivers, E., Hasson, F., and Slater, P., 2017. Pre-registration nursing student's quality of practice learning: Clinical learning environment inventory (actual) questionnaire. Nurse Education Today. 55, 58-64.

Schneider, A.R., Stephens, L.A.M., Ochoa Marín, S.C., Semenic, S., 2018. Benefits and challenges of a nursing service-learning partnership with a community of internallydisplaced persons in Colombia. Nurse Education in Practice 33, 21-26.

Sundler, A., J., Björk, M., Bisholt, B., Ohlsson, U., Engström, A., K,. Gustafsson, M, 2014. Student nurses' experiences of the clinical learning environment in relation to the organization of supervision: A questionnaire survey. Nurse Education Today, 34(4), 661-666. doi.org/10.1016/j.nedt.2013.06.023.

Williamson G.R., 2003. Misrepresenting random sampling? A systematic review of research papers in the Journal of Advanced Nursing. Journal of Advanced Nursing 44, 278-288.

Williamson, G., R., Health, V., and Proctor-Childs, T., 2013. Vocation, Friendship and Resilience: A Study Exploring Nursing Student and Staff Views on Retention and Attrition. The Open Nursing Journal, 2013, 7, 149-156 149

World Health Organisation, 2011. Global Health and Aging, Chicago: World Health Organisation. 